Misr J. Ag. Eng., 26(4): 1965- 1972

BIOLOGICAL ENGINEERING

\title{
A NOVEL AND SIMPLE TECHNIQUE FOR THE DETERMINATION OF QUANTITY OF ALCOHOL PRODUCED IN WET PADDY RICE DUE TO FERMINTATION
}

\author{
M.M. Naim ${ }^{*}$ M.E. Yehia ${ }^{* *}$ A.B. El-Abd ${ }^{* * *}$
}

\begin{abstract}
A novel and simple technique was devised to determine the quantity of ethanol produced in wet paddy rice due to fermentation, after harvesting. Undried rice has the potential of developing ethanol during storage due to fermentation. The latter process which is affected by both temperature and time, converts sugars to alcohol by the action of yeast, which is an undesirable process. A simple technique by which the quantity of alcohol produced is evaluated, as a function of both time and ambient temperature, has been applied, in which the alcohol-containing rice is leached by distilled water for a time $\geq e q u i l i b r i u m ~ t i m e$, followed by rapid filtration and the leachate's density is determined by weighing a standard volume of the leachate, followed by determining the concentration of ethanol from standard tables of densities of alcohol - water mixtures cited in the literature. The amount of alcohol is drawn versus the densities and the time after harvest (non ventilation) and finally equations for percent alcohol versus time of non ventilation and percent alcohol versus density are developed. High correlation coefficients (>0.991) are obtained in both cases. The equations could be used for the rapid estimation of percent alcohol as a function of both time and density.
\end{abstract}

Key words: paddy, fermentation, storage conditions, ethanol, fungi, yeast.

\section{INTRODUCTION}

$\mathrm{M}$ anaging rice decay during storage is a serious problem which must be obviated. The cause of rice decay is the presence of fungi of various types contaminates rice while it grows in the field.

Under high moisture and high temperature conditions, some fungi may

*Prof. Chemical Eng. Dept., Eng. Fac., Alex. Univ.

${ }^{* *}$ Researcher, Rice Technology Training Center, Alex. A.R.C.

** Senior research, Rice Research \&Training Center, Sakha, Kafer ElSheikh, A.R.C. 
developed before harvest. The main field fungi (molds) require an equilibrium relative humidity of $95-100 \%$. This corresponds to grain moisture content of above $22 \%$. After the rice is harvested and the rice dries down, the field fungi die and a different group of fungi develop (storage fungi). Similar to field bacteria, field fungi can be extremely detrimental to rice quality if the freshly harvested rice is not adequately aerated.

Fungi are a major cause of reduction in the quality of stored rice. They are often the role cause of spoilage when insects and rodents are controlled. Moreover, fungi and insects frequently exist symbiotically. A funguscarrying insect can introduce the disease by feeding on the grains. Fungiinduced spoilage is prevented by the consistent application of well defined grain storage management practices. A wide variety of microfauna and microflora, such as bacteria, protozoa, yeast and fungi are found on or in cereal grains. Active growth of bacteria can be avoided by minimizing the time period from harvesting to drying; otherwise, serious quality loss takes place.

Rice grains become infected in transport equipment or at the elevator where the grain is dried and stored; unlike the field fungi since the former grow at equilibrium relative humidity's as low as $70 \%$ where there is no free water and at temperatures down to $24^{\circ} \mathrm{F}$. The common storage fungi are several species of Aspergillus and Penicillium, the development of which is an indication of the moisture content of the stored grain.

Rice held at moistures above $22 \%$ to $24 \%$ is particularly subject to the microbial activity that causes formation of volatile organic compounds. Laboratory and field studies demonstrated that undried rice has significant potential for developing off-odors as measured by ethanol formation. Aeration of wet rice and rapid drying can be used to reduce off-odor development for rice varieties that must be harvested at high moisture (James et al, 2001). Fermentation is the process where yeast converts sugars to alcohol. The most commonly used yeast is Saccharomyces cerevisiae (SC) (Pretorius, 2000) because it can produce ethanol to a concentration as high as $18 \%$ in the fermentation broth. SC is also generally recognized as safe (GRAS) as a food additive for human consumption (Lin and Tanaka, 2006). Pre-fermentation is done to achieve the desired number of yeast cells for fermentation and is a process that involves agitation for 10-12 hours to achieve 300-500 million cells/milliliter. Fermentation takes place at a 
temperature of about $33^{\circ} \mathrm{C}$ (Thomas et al., 1996), at a pH of about 4.0 (Neish and Blackwood, 1951), and lasts between 48-72 hours (Ingledew, 1998). Torija et al. (2003) reported that the optimum temperature for reproduction and fermentation in yeast is 28 and $32^{\circ} \mathrm{C}$, respectively. Fermentation efficiency of SC at temperatures above $35^{\circ} \mathrm{C}$, is low (Banat et al., 1998).

Physical damage includes reducing milling quality which may be happen due to putting the wet rice after harvesting in plastic bags or in the trucks a long time before drying. Harvesting at the right grain moisture content and avoiding delays in threshing and drying are recommended in order to avoid fissuring and excessive grain breakage. Also threshing and drying rice grain as soon as possible should take place after cutting.

Ideally, rice should not remain in trucks overnight. A delay in aerating wet rice can reduce quality characteristics, such as taste, which is important in some export markets. Studies have shown that no aerated wet rice begins to produce ethanol within hours of harvest. For that reason, putting wet rice in the trucks or in the plastic bags immediately after harvest without aeration should be avoided .The percent of whole milled grain (head rice) is highest when rice is harvested at moisture content greater than what is required for safe storage. Timing, field draining, and harvesting are keys to high head rice yields. As Geng, et al.(1984) studied that early harvesting may reduce yield due to the presence of immature kernels. Late harvesting may also reduce yield on account of grain shattering and lodging. However, while moisture content is very important, there are many factors determining milling quality. Accordingly, the present study aims to develop a novel and simple technique for determination of quantity of alcohol produced in wet paddy rice due to fermentation.

\section{MATERIALS AND METHOD}

The present study was carried out during 2007 rice growing season. A sample of the rice variety Sakha 101 grown under the normal conditions at the farm of Rice Research \& Training Center, Sakha, Kafr El-Sheikh, was utilized to determine quantity of alcohol produced in wet paddy rice due to fermentation at the laboratory of Chemical. Eng. Dept., Faculty of Engineering, Alex. University and Rice Technology Training Center,. Alex., Egypt. 


\section{Procedure}

Into six tiny wide mouthed plastic polypropylene bottles fitted with tight threaded plastic cover to form a seal, about 50 grams of wet paddy rice, weighed on an electric balance to the fourth decimal place, are added to each bottle followed by pipetting exactly $100 \mathrm{ml}$ of distilled water. The ambient temperature is recorded. The bottles are shaken on an electric shaker, each for a different time interval, during which the ethanol present in each bottle is leached out of the paddy rice grains with the surrounding distilled water. This experiment has to be done initially in order to determine the minimum shaking time required for equilibrium ethanol concentration to be reached. One bottle at a time is analyzed for ethanol at different time intervals up to a maximum of three hours respectively.

\section{Analysis of leachate for ethanol}

The quantity of ethanol in the equilibrium liquid phase is determined as follows:

$10 \mathrm{ml}$ of the leachate are pipetted into a pre-weighed weighing bottle containing a sintered glass cover (to the $4^{\text {th }}$ decimal place) then the bottle is covered tightly and reweighed. The weight of leachate is divided by the volume of the pipette $(10 \mathrm{ml}$ in the present case). The density of the ethanol water mixture is then determined. The densities of the mixtures, then the concentrations (as percent b.w.) can be determined from standard tables for concentration of ethanol in ethanol - water mixtures versus density which ranges from $100 \%$ alcohol to $100 \%$ water $(0.7900-1.0000 \mathrm{~g} / \mathrm{ml}$ respectively) (John, 1963). The results are then plotted as \% alcohol (b.w.) on the ordinates versus time of shaking in hrs on the abscissa. The curve starting at the point of origin should gradually increase until a highest concentration is reached then levels off with time. The time at which the highest concentration is first attained is the minimum time necessary for shaking to take place.

It should be mentioned that if 3 hours are found not be enough and that extra shaking time is accordingly required to leach more alcohol, further experiments are required at larger time intervals. This minimum required shaking time is essential to be determined actually for each different condition in order to be able to quantify the ethanol produced under various conditions. 


\section{RESULTS AND DISCUSSIONS}

Figure (1) presents the plot indicating the minimum time of shaking required to reach equilibrium. The figure shows that, the minimum time of shaking in each experiment should not be less than three hrs in order that complete leaching of ethanol to form a constant concentration of alcohol inside and outside the rice grain takes place.

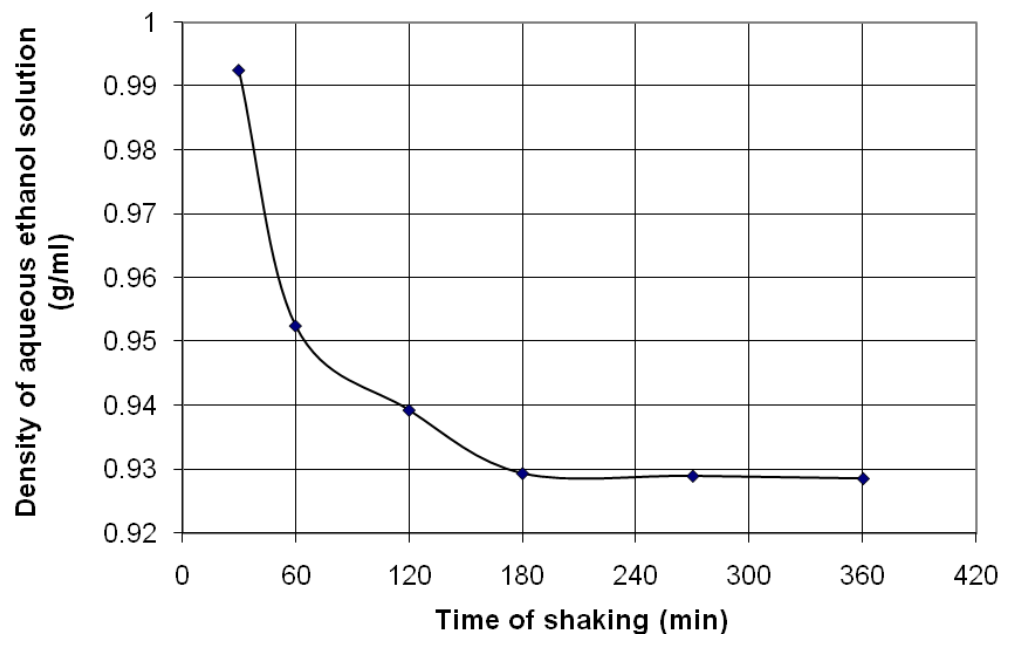

Figure (1): Plot of determination of equilibrium time of shaking

Figure (2) relates the percent ethanol in the ethanol-water mixture with the time of non-ventilation of paddy rice grains. As expected the concentration of ethanol is in direct proportionality with the time of non-ventilation.

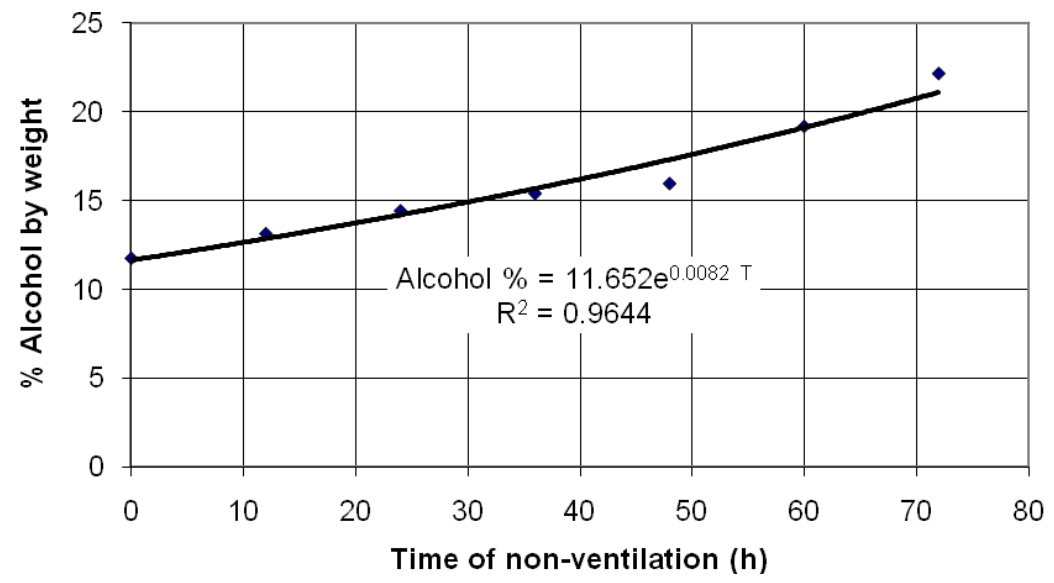

Figure (2): Plot of \% alcohol (b.w.) vs. time of non-ventilation of paddy. 
Figure (3), which relates the density of aqueous ethanol solution to the time of non-ventilation, allows the densities to be determined at any time from the obtained fitted equation.

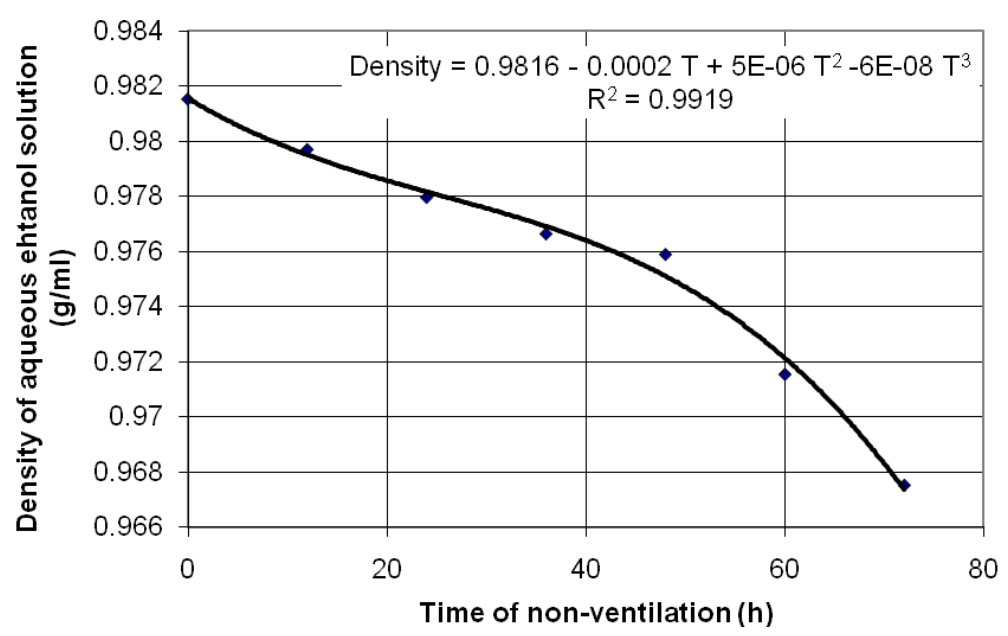

Figure (3): Plot of density of ethanol vs. time of non-ventilation of paddy

As to figure (4), the plot presents the relation between \% concentration and density of the alcohol-water mixture as determined from the table cited in the literature in given range of experiments.

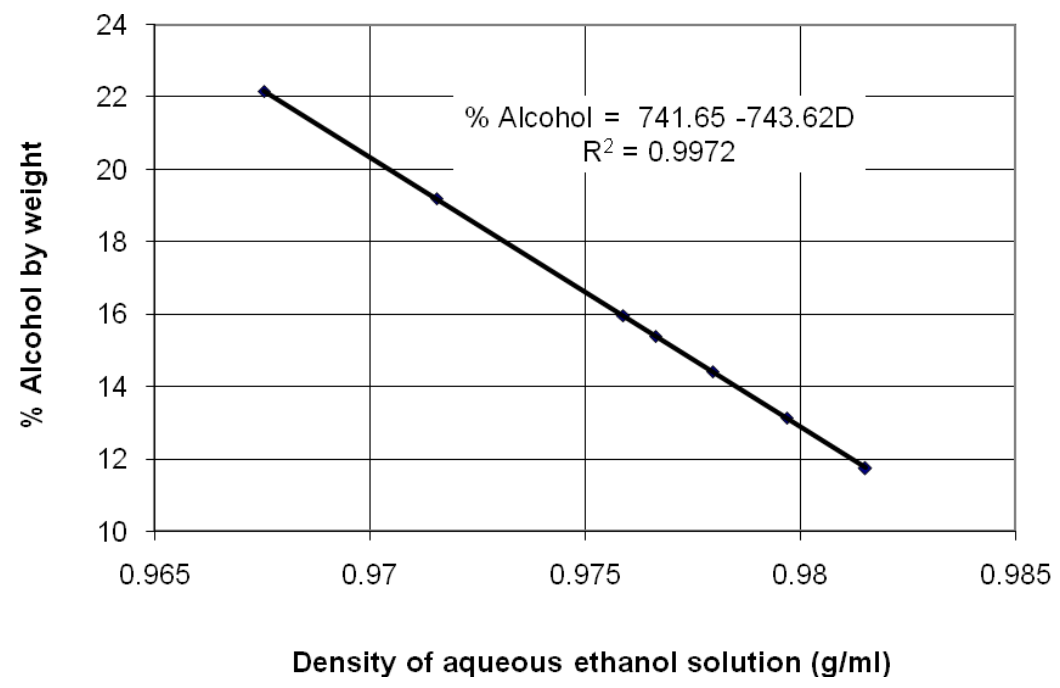

Figure (4): Plot of concentration of ethanol-water mixtures vs. their respective densities. 


\section{CONCLUSION}

From the aforementioned paragraphs it has been shown that mathematical relations correlating percentage ethanol in stored wet paddy rice with time and with density of ethanol-water mixtures have been developed from which the percent alcohol could be computed readily. As aforementioned the percentage alcohol sheds light on the extent of fermentation of the paddy rice from the moment of harvest until the paddy rice is either dried in fields or stored in bins.

Equations are very accurate as shown by values of the correlation coefficients approaching unity. The method is straightforward, simple, and does not need any sophisticated equipment for analysis such as gas chromatography or otherwise. The method could be applied to different types of paddy rice or other cereals providing that their pertaining correlations are determined.

\section{REFERENCE}

Banat, I.M., P. Nigam, D. Singh, R. Merchant, and A.P. McHale. 1998." Ethanol production at elevated temperatures and alcohol concentrations": A review; Part-I Yeast In General. World J. Microbiol. Biotechnol. 14:809-821.

Geng, S., J.F. Williams, and J.E. Hill. 1984." Harvest moisture effects on rice milling quality". In California Agriculture, Nov.-Dec: 11-12.

Ingledew, W.M. 1998. "Alcohol production by Saccharomyces cerevisiae": A yeast primer. Chapter 5 In: The alcohol textbook. 3rd ed. K.A. Jacques, T.P. Lyons and D.R. Kelsall Ed. Nottingham University Press. Nottingham,UK.

James F. Thompson, R. G. Mutters, David C. Slaughter, Jerry Knutson, and Eunice Tan 2001."Preventing off- odor development in undried rice", ASAE Annual Meeting Paper number 016109.

John H. Perry, ed.1963."Chemical engineers' handbook" Fourth Edition, Densities of aqueous organic solutions, McGraw-Hill Book Comp. Inc.

Lin, Y., S. Tanaka. 2006." Ethanol fermentation from biomass resources": current state and prospects. Appl. Microbiol. Biotechnol. 69: 627-642.

Neish, A.C., and A.C. Blackwood. 1951. "Dissimilation of glucose by yeast at poised hydrogen ion concentrations". Canadian Journal of Technology. 29:123-129. 
Pretorius, I.S. 2000."Tailoring wine yeast for the new millennium": Novel approaches to the ancient art of winemaking. Yeast 16:675-729.

Thomas, K.C., S.H. Hynes, and W.M. Ingledew. 1996." Practical and theoretical considerations in the production of high concentrations of alcohol by fermentation". Proc. Biochem. 31:321-331.

Torija, Ma. J., N. Rozès, M. Poblet, J.M. Guillamón, and A. Mas. 2003." Effects of fermentation temperature on the strain population of Saccharomyces cerevisiae" . International Journal of Food Microbiology. 80: 47-53.

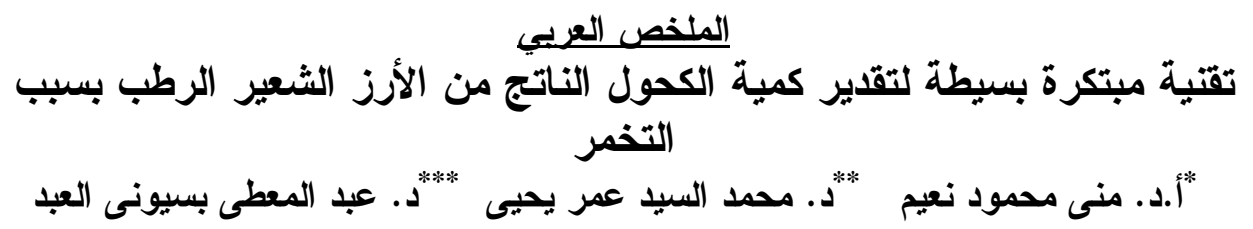

باستخدام تقنية بسيطة تم وضعها في هذا البحث أمكن تقدير كمية الايثانول الناتجـة من التخمر في

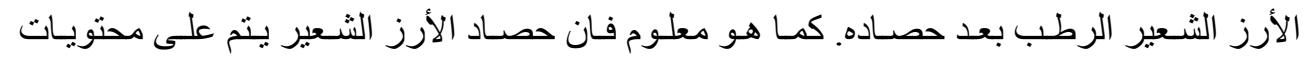

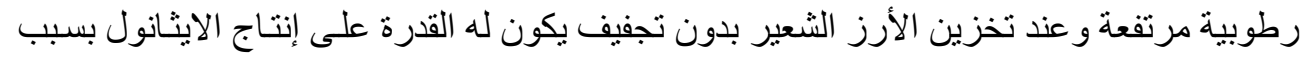

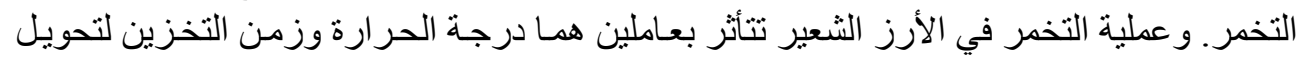

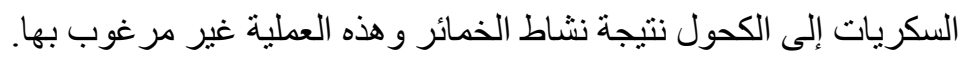

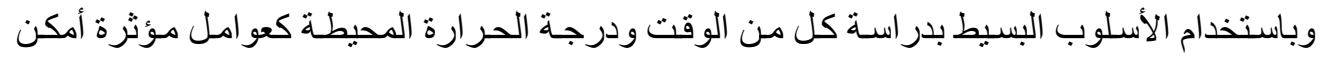

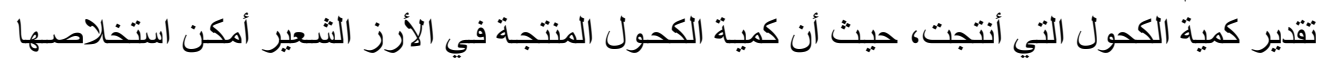

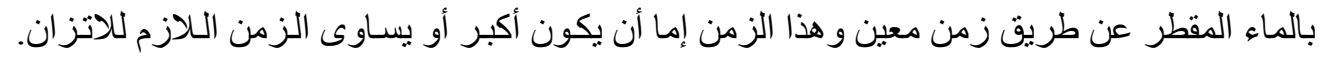

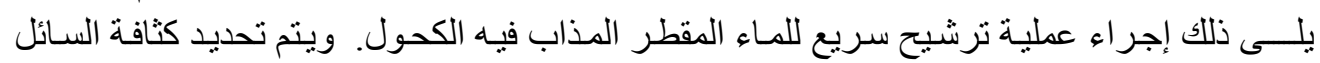

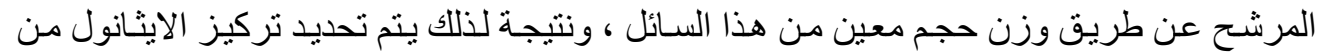

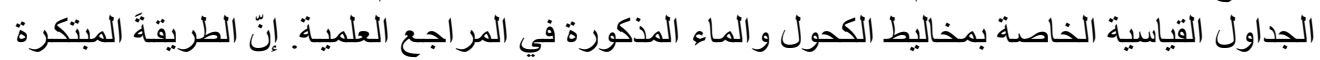

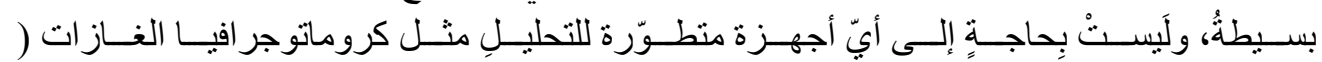
(gas chromatography

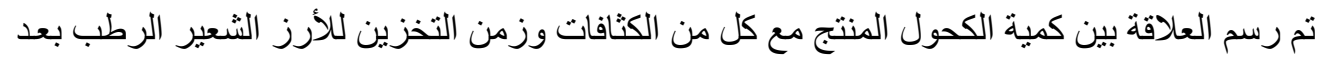

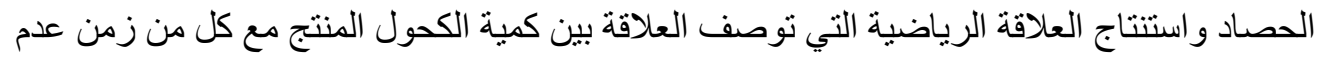

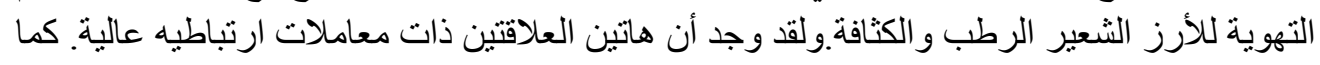

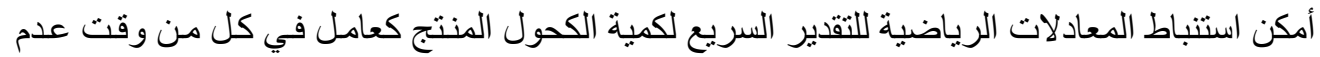
التهوية و الكثافة.

$$
\begin{aligned}
& \text { "أستاذ الهندسة الكيمائيةـ كلية الهندسة- جامعة الإسكندرية } \\
& \text { *باحث بمركز تدريب تكنولوجيا الأرز } \\
& \text { ب***قاحث أول مركز تدريب الأرز بسخا }
\end{aligned}
$$

